\title{
A sea of uncertainty
}

\author{
JASON A. LOWE AND JONATHAN M. GREGORY
}

\section{How well can we predict future sea level rise?}

\section{A} crucial question for sea level rise in the twenty-first century is how much ice will be lost from the Greenland and Antarctic ice sheets as a result of rapid accelerations in ice flow. This issue was highlighted by the Intergovernmental Panel on Climate Change (IPCC) in its 2007 assessment report ${ }^{1}$. They concluded that "understanding of these effects is too limited ... to provide a best estimate or an upper bound for sea level rise" in the twenty-first century. Excluding these effects, they projected a sea level rise of $0.26-0.59$ metres by the 2090s for their highest-emissions scenario.

The available evidence still doesn't allow us to say with certainty whether sea level rise could exceed the IPCC's projections. Observations, largely from satellites, show that both ice sheets are losing mass overall ${ }^{2}$, and faster than changes in melting and snowfall would cause by themselves ${ }^{3,4}$. This is due to the speed-up of many outlet glaciers on Greenland and ice streams in the West Antarctic Ice Sheet, which discharge ice into the sea. Consequently, these ice sheets are probably making a substantially greater contribution now to sea level rise than they did during the twentieth century on average.

New research suggests that the possibility of sea level rise of up to two metres by 2100 should be given serious consideration. One key study ${ }^{5}$ examined the ice flow rates that would be required to produce substantial sea level rise by 2100 and concluded that a rise of much more than two metres would be "physically untenable". Although increases of up to two metres could not be excluded, a sea level rise of less than one metre by 2100 was judged more likely on grounds of physical plausibility. Proxy evidence from oxygen isotope ratios in Red Sea sediment cores ${ }^{6}$ suggests that sea level rose by as much as 1.6 metres per century at a time in the past when the large ice sheets covered an area similar to their present-day extent.

Although increases of up to two metres this century can't be ruled out, this does not mean that they are inevitable or even likely. For climate change to produce much more than one metre of sea level rise, ice sheets would probably have to contribute

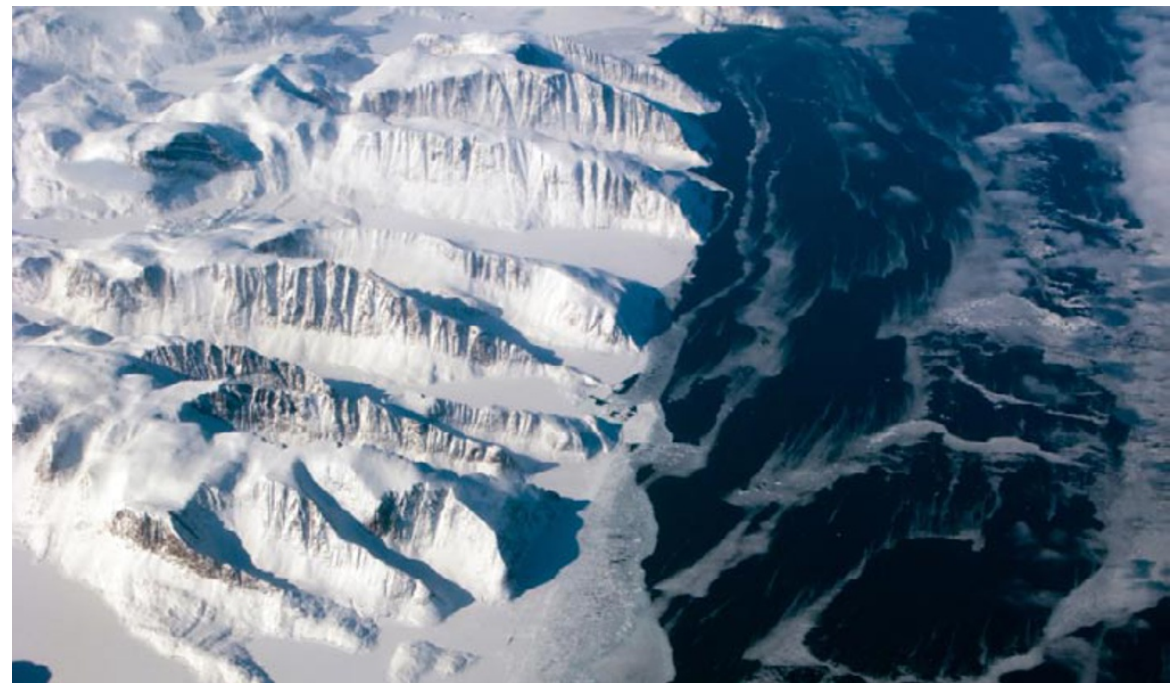

For sea level to rise by more than one metre, the contribution from the Greenland and West Antarctic Ice Sheets would have to increase considerably in the future.

considerably more to the rise than they do now; one 2009 study put their current contribution at 0.15 metres per century ${ }^{2}$. The recent acceleration of Greenland outlet glaciers and Antarctic ice streams may be due in part to natural variability, and it might not continue. Some observations indicate that a number of the outlet glaciers and ice streams that accelerated in the 1990s have since started to slow down ${ }^{7}$, and a recent study based on detailed modelling of the Helheim glacier on Greenland suggested that "recent rates of mass loss in Greenland's outlet glaciers are transient and should not be extrapolated into the future"s.

\section{NOT ADDING UP}

In this sea of uncertainty, how do we derive a better estimate of sea level rise? While we await the development of climate models that include a more realistic treatment of ice-sheet processes, some researchers have taken a more empirical approach to estimating sea level rise.

Rather than modelling the different processes that contribute to sea level rise and summing them, these semi-empirical methods obtain a quantitative relationship between past global sea level and temperature change $e^{9-11}$ or radiative forcing ${ }^{12}$, typically derived from the last century or so, but sometimes longer. The approach is loosely based on an understanding of physical processes, but the relationship is determined by statistical methods. The general assumption is that the relationship between sea level rise and temperature (or forcing) will hold in the future and for a much greater range of warming than occurred during the period from which it was calibrated. If this assumption is valid, it allows estimates of future sea level rise to be calculated directly from climate model predictions of global warming. Several studies give projections in the range of one to two metres by 2100 , much greater than the IPCC projection ranges. It is thus critical to ask whether semi-empirical approaches can be used to provide robust projections suitable for planning purposes.

There has already been some debate about the statistical validity of these approaches ${ }^{13-15}$, but it is also important to consider what semi-empirical methods imply regarding possible contributions to sea level rise. Are their predictions of substantially more than one metre of sea level rise in the twenty-first century physically reasonable? And why do these 
methods give larger projections than IPCC models? It seems unlikely that semi-empirical methods can predict large dynamical changes in ice sheets if they have been calibrated against observations from recent centuries, because the evidence suggests that the contribution of ice sheets to sea level rise was small before the last couple of decades. Of the projected future sea level rise, a proportion would be contributed by the melting of glaciers and ice caps (excluding Greenland and the Antarctic $)^{1}$, but even their total loss would be unlikely to produce more than around 40 centimetres of rise, and their contribution could be considerably less ${ }^{16}$. According to current understanding of the rate at which the deep ocean takes up heat, it is also unlikely that thermal expansion could be large enough to bring the total twenty-first-century sea level rise to almost two metres. Combined, the loss of ice from glacial melting and thermal expansion of the ocean do not produce such a large future sea level rise as predicted by semiempirical models.

Adding up the estimates of the various observationally derived contributions to historic sea level rise, which all have uncertainties, we find that their sum may fall short of the measured total sea level rise. The semi-empirical methods assume that any difference is due to a missing contribution that will increase with global warming. Though that assumption may be correct, without understanding/identifying the physical processes that may make up this shortfall in sea level, there is little in the way of supporting evidence.

For society, ignoring the need for adaptation could prove costly, but so could overcommitting to adaptation, a potential outcome of placing too much confidence on upper estimates of sea level rise. The climate science community needs to communicate effectively that sea level rise is likely to continue, but that the rise by the year 2100 is almost certain to be below two metres and that there is currently very little evidence to suggest that increases at the top of this range are likely. It is vital to continue to monitor sea level and its components and to develop a capability to make reliable projections. Meanwhile, as we cannot provide certainties, we must become better at explaining the uncertainties to decisionmakers. These uncertainties imply a need to keep open a range of adaptation options and to be able to change the approach as the predictions become more robus $\mathrm{t}^{17}$.
Published online: 6 April 2010

\section{doi:10.1038/climate.2010.30}

References

1. IPCC. Climate Change 2007: The Physical Science Basis (eds Solomon, S. et al.) 356-369, 408-420, 812-822 (Cambridge University Press, Cambridge, UK, and New York, 2007).

2. Velicogna, I. Geophy. Res. Lett. 36, L19503 (2009).

3. Pritchard, H. D., Arthern, R. J., Vaughan, D. G. \& Edwards, L. A. Nature 461, 971-975 (2009).

4. Van den Broeke, M. et al. Science 326, 984-986 (2009).

5. Pfeffer, W. T., Harper, J. T. \& O'Neel, S. Science 321, 1340-1343 (2008)

6. Rohling, E. J. et al. Nature Geosci. 1, 38-42 (2007).

Kerr, R. Science 323, 458 (2009).

8. Nick. F. M., Vieli, A., Howat I. M. \& Joughin, I. Nature Geosci. 2, 110-114 (2009).

9. Rahmstorf, S. Science 315, 368-370 (2007).

10. Vermeer, M. \& Rahmstorf, S. Proc. Natl Acad. Sci USA 106, 21527-21532 (2009).

11. Grinsted, A., Moore, J. C. \& Jevrejeva, S. Clim. Dynam. 34, 461-472 (2010).

12. Jevrejeva, S., Moore, J. C. \& Grinsted, A. Geophys. Res. Lett. doi:10.1029/2010GL042947 (in the press).

13. Holgate, S., Jevrejeva, S., Woodworth, P. \& Brewer, S. Science 317, 1866 (2007).

14. Schmith, T., Johansen, S. \& Thejll, P. Science 317, 1866 (2007) 15. Rahmstorf, S. Science 317, 1866 (2007).

16. Raper, S. C. B. \& Braithwaite R. J. Nature 439, 311-313 (2006). 17. Lowe, J. A. et al. UK Climate Projections Science Report: Marine and Coastal Projections 85-90 (Met Office Hadley Centre, Exeter, UK, 2009); http://bit.ly/clxWuU

Jason Lowe is based at the UK Met Office, and Jonathan Gregory is based at both the UK Met Office and the University of Reading, UK. e-mail: jason.lowe@metoffice.gov.uk

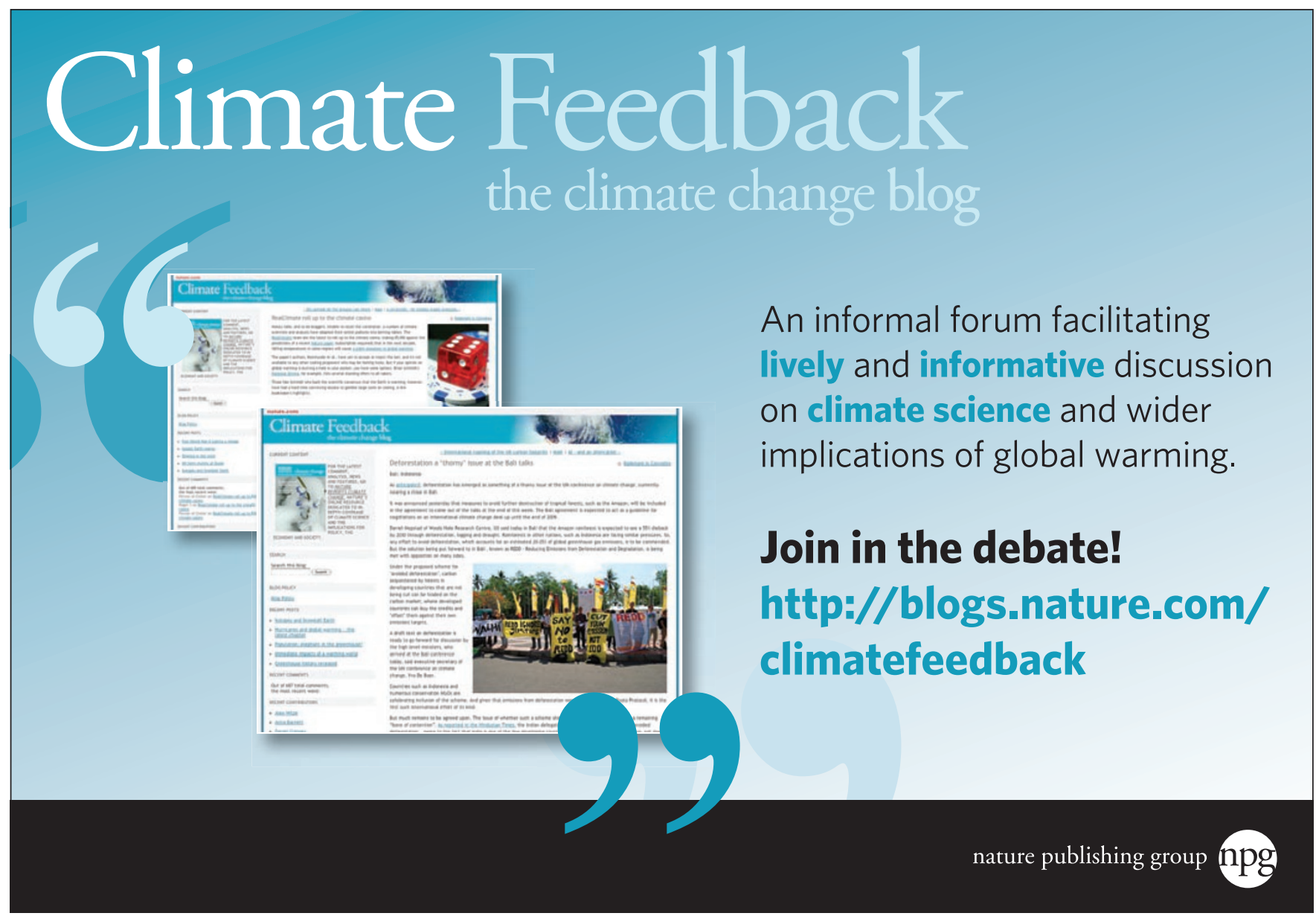

